\title{
Dietary intakes and body composition in adult patients with long-standing Crohn's disease currently in remission
}

\author{
E. M. O'Connor ${ }^{1}$, F. Shanahan ${ }^{2}$ and K. D. Cashman ${ }^{1,2}$ \\ ${ }^{1}$ Department of Food and Nutritional Sciences and ${ }^{2}$ Department of Medicine, University College Cork, Republic of Ireland
}

Weight loss and low body fat have been reported in adult patients with Crohn's disease $(\mathrm{CD})^{(1,2)}$. In addition, deficiencies in several nutrients have also been reported in patients with $\mathrm{CD}^{(3)}$, but it is not clear whether these deficiencies arise as a consequence of inadequate intake and/or poor intestinal absorption and increased requirement, as a result of disease. The aim of the study was to compare dietary intakes and body composition of a group of adult patients with long-standing CD, currently in remission, with that of a group of age- and gender-matched healthy control subjects.

Forty adult patients with CD (eighteen men and twenty-two women), currently in remission and with long-standing ( $>5$ years) disease, were recruited from the Inflammatory Bowel Disease Clinic of Cork University Hospital. Remission was defined at the time of study as the absence of gastrointestinal symptoms and not requiring therapeutic doses of corticosteroids. Forty age- and gender-matched healthy control subjects were recruited from the Cork City area. Dietary intake was estimated using a 7-day diet history and analysed for nutrients using WISP (Weighted Intake Software Program) (Tinuviel Software, Warrington, UK). All statistical analysis was carried out using SPSS version 15.0 (SPSS Inc., Chicago, IL).

There was a significant $(P<0.01)$ difference in the proportion of patients with $\mathrm{CD}$ and healthy controls that were classified (on basis of BMI) as being underweight, normal weight, overweight or obese. There were no significant differences in waist circumference $(P=0.41)$, hip circumference $(P=0.63)$, percentage body fat $(P=0.1)$ mid-arm muscle area $(P=0.27)$, biceps $(P=0.55)$ and subscapular $(P=0.22)$ skinfold thickness measurements in either group. Skinfold thickness measurements at the supra-iliac and triceps sites were significantly $(P=0.03)$ and borderline significantly $(P=0.08)$ different respectively between patients with $\mathrm{CD}$ and healthy matched controls.

\begin{tabular}{lccc}
\hline & \multirow{2}{*}{$\begin{array}{c}\text { BMI category } \\
\left(\mathrm{kg} / \mathrm{m}^{2}\right)\end{array}$} & Patients with CD $(n$ 40) & Matched controls $(n$ 40) \\
\cline { 3 - 4 } Weight category & $<18$ & 1 & 0 \\
Underweight & $18-25$ & 19 & 10 \\
Normal weight & $>25$ & 9 & 24 \\
Overweight & $>30$ & 11 & 6 \\
Obese & &
\end{tabular}

The mean daily intake of several macronutrients and micronutrients was similar in patients with $\mathrm{CD}$ and controls. The patients with $\mathrm{CD}$ had significantly $(P<0.05-P<0.001)$ lower mean daily intakes of some micronutrients $(\%$; $\mathrm{K} \mathrm{20,} \mathrm{Mg} 24, \mathrm{P} 13$, total Fe $26, \mathrm{Cu} 16, \mathrm{Zn} 13$, Mn 22, $\beta$-carotene 16, thiamine 17, niacin 15, total folate 23, biotin 25 and vitamin (vit) $C$ 40) compared with those for control subjects. The percentage below the European estimated average requirement ${ }^{(4)}$ for all patients with $\mathrm{CD}(n$ 40) $v$. controls $(n 40)$ was:

\begin{tabular}{lcccccccrrrrrr}
\hline & $\mathrm{K}$ & $\mathrm{Ca}$ & $\mathrm{Mg}$ & $\mathrm{Fe}$ & $\mathrm{Zn}$ & $\mathrm{Se}$ & $\mathrm{I}$ & $\mathrm{Vit}$ A & Vit E & Thiamine & Riboflavin & Niacin & Vit C \\
\hline CD & 25 & 8 & 3 & 30 & 6 & 30 & 15 & 55 & 10 & 3 & 10 & 5 & 13 \\
Control & 15 & 5 & 0 & 13 & 0 & 28 & 23 & 58 & 0 & 10 & 0 \\
\hline
\end{tabular}

In conclusion, the study showed that patients with $\mathrm{CD}$ had inadequate intakes of a number of micronutrients, which may contribute to deficiencies or suboptimal status for these nutrients.

1. Jahnsen J, Falch JA, Mowinckel P \& Aadland E (2003) Am J Gastroenterol 98, 1556-1562

2. Capristo E, Mingrone G, Addolorato G, Greco AV \& Gasbarrini G (1998) J Intern Med 243, 339-347.

3. Geerling B, Badart-Smook A, Stockbrugger RW \& Brummer RJM (1998) Am J Clin Nutr 67, 919-926.

4. Scientific Committee for Food. Nutrient and Energy Intakes for the European Community. Reports of the Scientific Committee for Food, $31^{\text {st }}$ series. Luxembourg: Office for Official Publications of the European Communities, 1993; 60-215. 